\title{
Simulation Method of Rolling Mill Process Control System with Actual Information
}

\author{
Zhijie Jiao $^{1, ~ a ~, ~ R u i y u ~ G a o ~}{ }^{1, b}$, Chunyu He $\mathrm{H}^{1, \mathrm{c}}$ and Jun Wang ${ }^{1, \mathrm{~d}}$ \\ ${ }^{1}$ State Key Lab of Rolling and Automation, Northeastern University, Shenyang 110819, China \\ ajiaozj@163.com
}

Keywords: Mill, PCS, Simulation, Actual information playback

Abstract. For the purpose of mill Process Control System (PCS) debugging and optimizing, a new simulation method is used. The actual information of rolling process is gathered and sent to the PCS cyclically. This information is saved by PCS. During simulation process, the actual information is read and playback. The PCS receives actual information just like actual rolling process. The simulation software is developed, and the functions of data gathering, data communication, data saving and playback are realized. The new PCS simulation method avoids the problem of traditional method, and the real site situation can be reappeared for the PCS function debugging.

\section{Introduction}

Process Control System (PCS) is the mainly part of the automation control system for the rolling mill. With PCS, setup data can be calculated with mathematic models for the rolling process. During designing, debugging and application of the PCS, there should have simulation method for better using of PCS. Currently, the simulation function module is designed in PCS, and with it, the trigger signals and actual data are simulated. This simulation actual information is generally produced through adding random disturbance to the model calculation information[1-8]. It is different from actual information. For better fitting of demand of PCS debugging and optimization, a new simulation method with actual rolling process information is presented.

\section{Simulation method of mill PCS}

System composition. Normally, the rolling mill automation control system is composed with level-system, and L2 PCS is the core part of whole system, as shown in Fig.1.

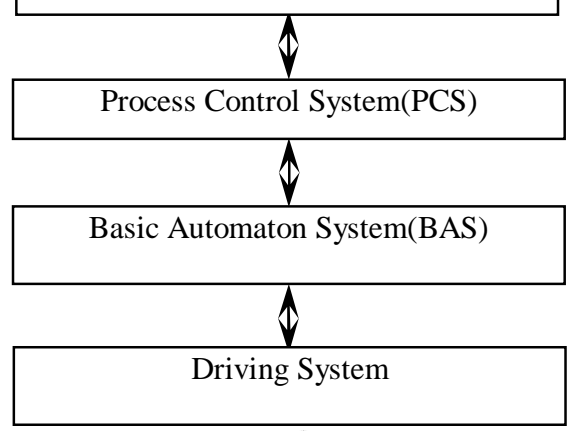

L0

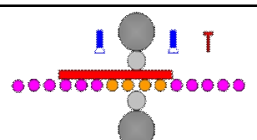

Fig.1 Rolling mill atuomation control system

Simulation function description. In PCS, these functions, such as data management, process tracking, model calculation, and data communication are included. All functions are realized with two processes, core function process and communication process. For the simulation purpose, the simulation process is added. The important thing of simulation is how to get the actual information. In order to avoid the shortcoming of current simulation method, the actual information is used for the 
simulation. During rolling process, the actual information is recorded by the PCS. And when the actual information is needed during simulation, the actual data can be playback. As shown in Fig.2, the actual data is gathered and transferred from BAS to PCS with data communication modules during rolling. And the actual data is distributed to the different function modules by process tracking module. For the simulation purpose, the actual information data is also transferred to the simulation process and be stored by data storage module. When the simulation function is used, the stored actual data can be read out from database and be sent to the process tracking module by data playback module.

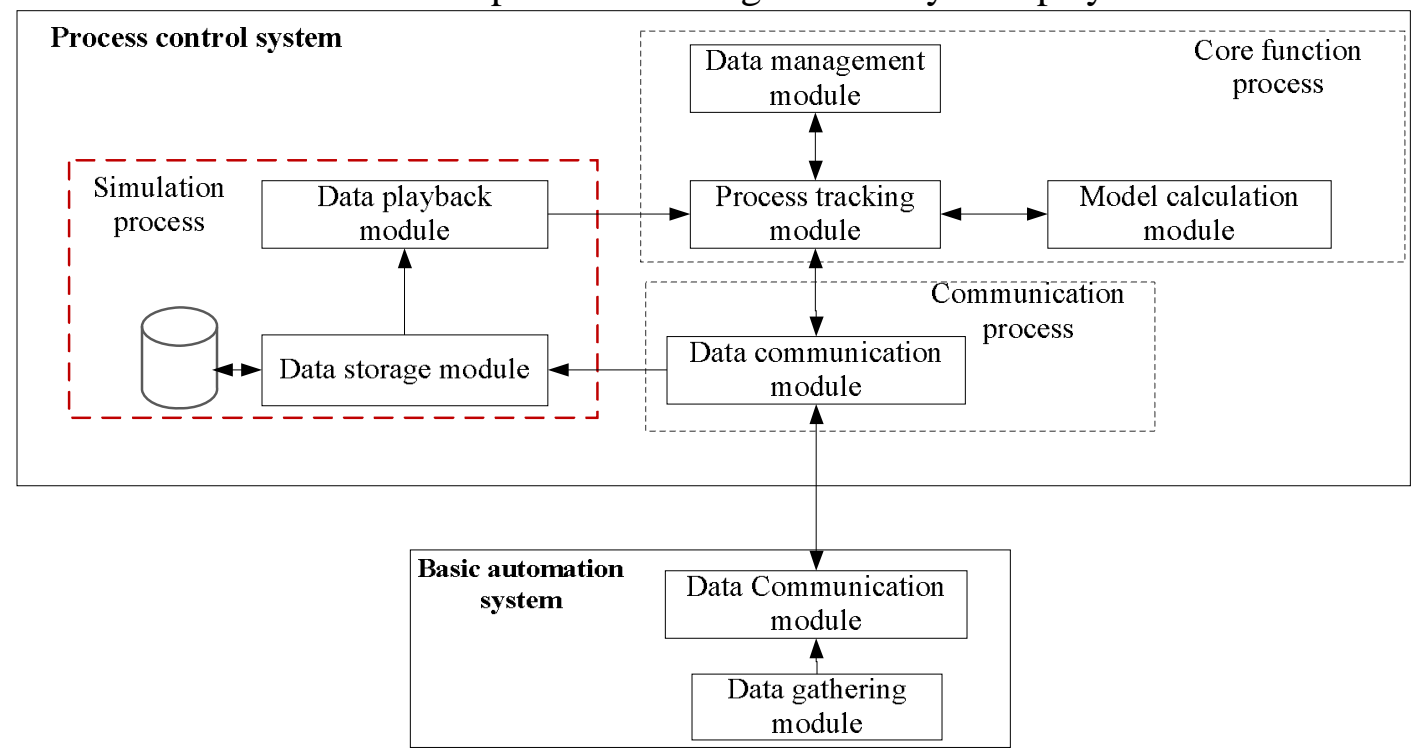

Fig. 2 Process control system and simulation process

Simulation function realization. Actual data information gathering: The actual information data is gathered by BAS. The actual information data includes actual rolling force, actual roll gap, actual temperature, which can be measured by the instrument. It also includes pass starting, pass ending and plate detection signals, which can be judged with detection signals by BAS. Data communication: The physical network connection between BAS and PCS is built with network card, cable and switch. And the software connection is built with the communication protocol. The actual information data is gathered and put into the data packet by BAS. Then the data communication module in BAS send data packet to PCS with time cycle. PCS data communication module receive data packet and treats it. The communication procedure is shown in Fig.3. Data storage: During rolling process, the actual information data that has been received by PCS should be saved. For the convenient of data access and management, the data can be saved with data file type according to the time order. One received data packet can be written as one data record. Also the data file can be named with the time rules. Data playback: During PCS simulation, the actual information data can be read form data file according to the time order periodically. And then the reading data is sent to the process tracking function module just like the actual rolling process.

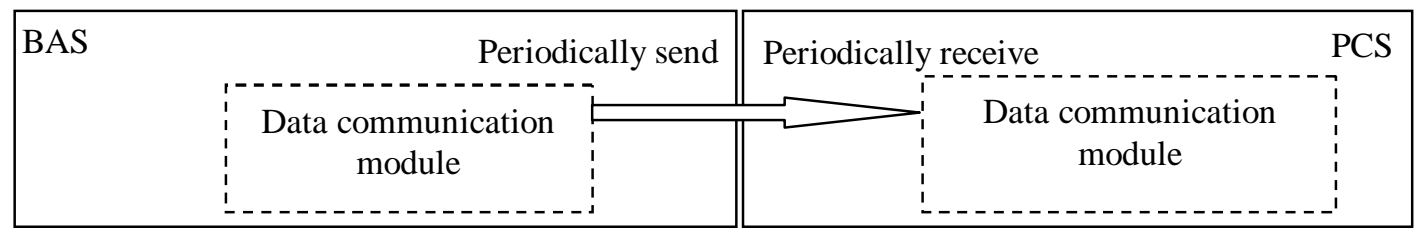

Fig.3 Data communication

\section{Application of simulation method}

Software development: The simulation process software functions are designed as shown in Fig.4. Data storage module is divided to data receiving function and data saving function. Data playback module is divided to data reading function and data sending function. Also the additional functions such as displaying and operation, data file selection, simulation start and stop functions are added. The 
software is developed with Visual $\mathrm{C}++$. The mainly pictures of PCS core function process software, communication process software and simulation process software are shown in Fig.5

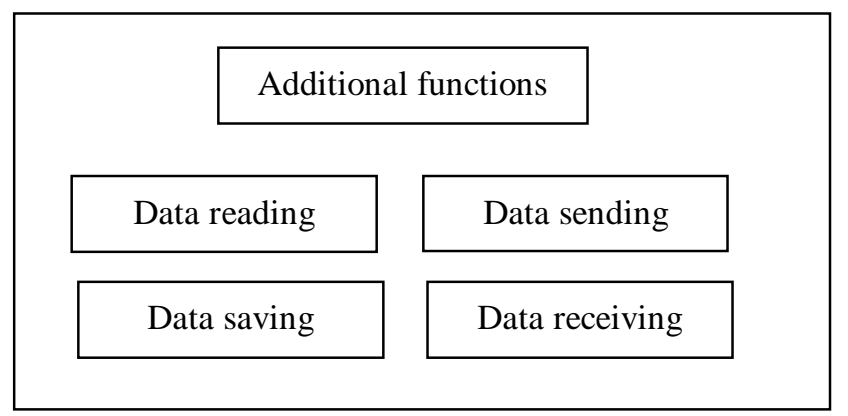

Fig.4. Simulation software functions

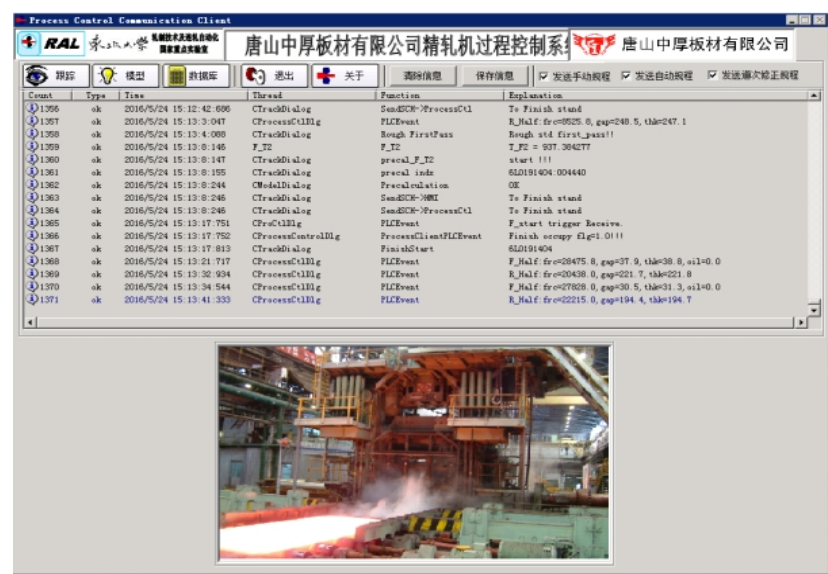

(a) PCS core function process software

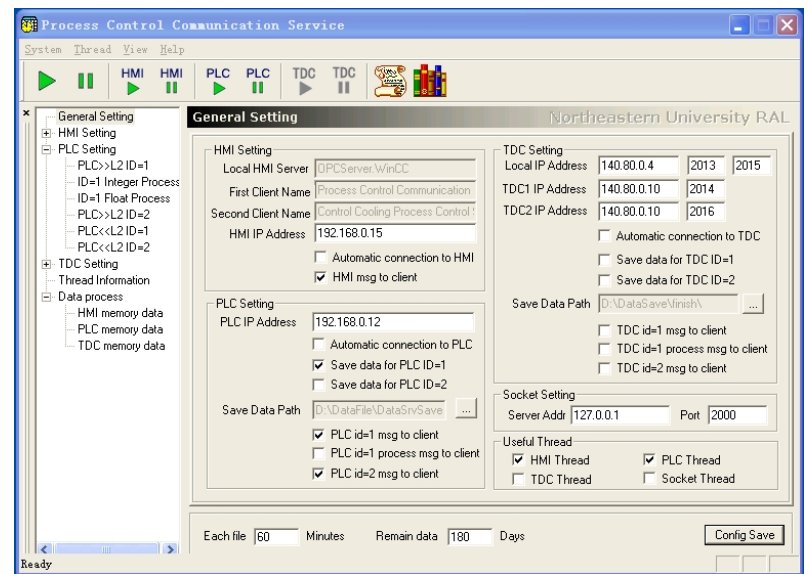

(b) PCS communication process software

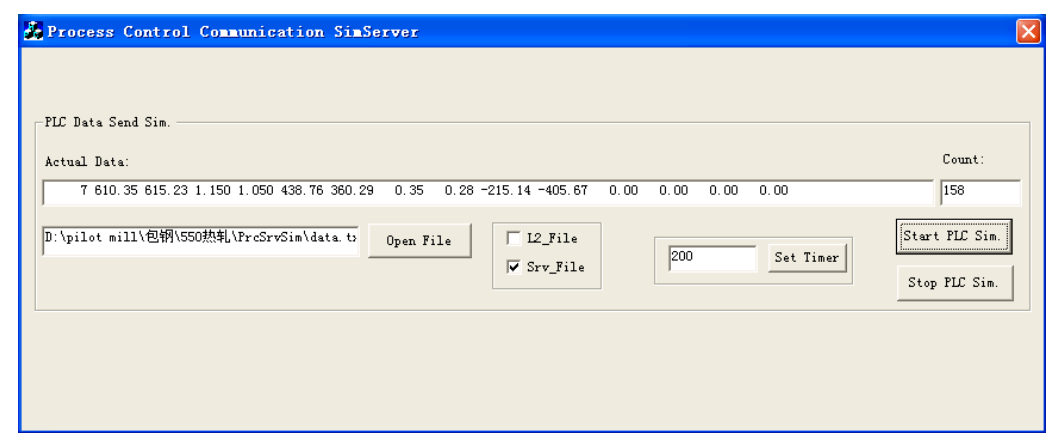

(c)PCS Simulation process software

Fig.5. Mainly picture of softwares

Application: For one plate mill, during rolling process, one pass rolling force is recorded as shown in Fig.6(a). And when the simulation function is used, the simulation data with actual data playback is used, the rolling force of this pass is shown in Fig.6(b). As shown in these two figures, the two curves are same completely. 


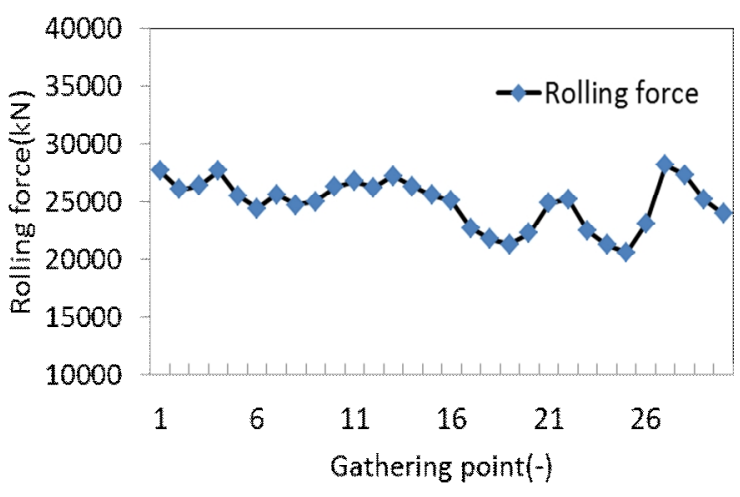

(a) Acutual rolling process

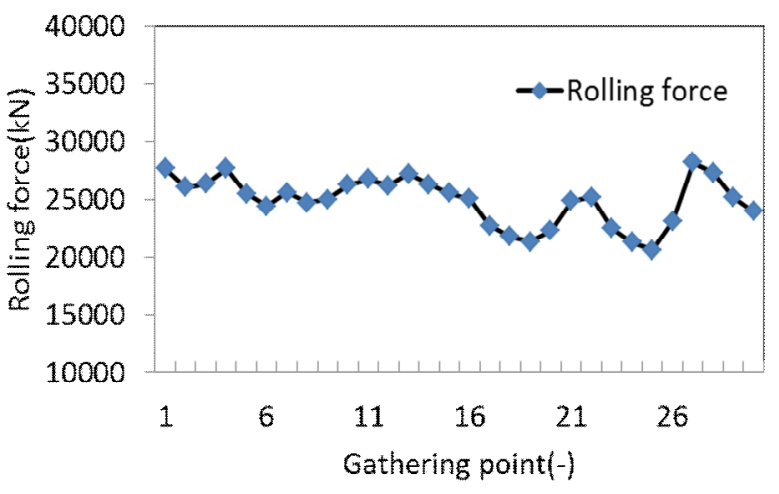

(b) Simulation rolling process

Fig.6. Rolling force data of acutual rolling process and simualtion process

\section{Conclusions}

For the purpose of Mill PCS debugging and optimization, a simulation method is applied with actual information data recording and playback. The problems of traditional simulation method are avoided, and the PCS control functions can be developed and optimized better.

\section{Acknowledgements}

This work was financially supported by the Fundamental Research Funds for the Central Universities (N120407007)

\section{References}

[1] X. G. Liu, L.N. Hao, X. H Xu, et al, Simulation support system and model base technology in cold rolling process control system, Proceedings of the 5th World Congress on Intelligent Control and Automation, Hangzhou, 2004, 3265-3268.

[2] C. L. Wang, P. J. Li, Z. H. Li, et al, Modeling and analysis for virtual rolling pieces of dynamic simulation system of rolling process, Proceedings of the 4th International Conference on Intelligent Information Technology Application, Beijing, 2010, 216-219.

[3] B. Zeng, J. Wu, H. H. Zhang, Numerical simulation of multi-pass rolling force and temperature field of plate steel during hot rolling, Journal of Shanghai Jiaotong University(Science), 16(2011) 141-144.

[4] Q. H. Wu, J. J. Cui, X. H. Xu, et al, Application of dis software methods in rolling process control simulation, Proceedings of the 4th Beijing International Conference on System Simulation and Scientific Computing, Beijing, 1999, 480-483.

[5] Z. L. Wang, Y. K. Sun, K. X. Peng, Real-time simulator of an AGC system for hot-rolling mill, Journal of University of Science and Technology Beijing, 28(2006) 171-174.

[6] L. Wang, L. Y. Cheng, Z. T. Liu, Simulation of hydraulic automatic position control in rolling mill system, Proceedings of the 10th International Conference on Steel Rolling, Beijing, 2010, 1580-1585 .

[7] Z. Y. Zhou, Q. Bao, Development of process control level strip rolling simulator system and its application in hot strip rolling plant test, Metallurgical Industry Automation, 2004, 6 20-25.

[8] C. N. Tong, Y. K. Sun, The simulation milling in hot strip mill computer control system, Journal of University of Science and Technology Beijing, 15(1993) 394-399 . 